\title{
Avaliação in vitro da eficiência de inóculos no tratamento anaeróbio de efluentes líquidos de suinocultura
}

[Efficiency of seeding material in anaerobic treatment of swine liquid waste: an in vitro trial]

\author{
L.S. Rodrigues ${ }^{1 *}$, I.J. Silva ${ }^{2}$, P.R. Oliveira ${ }^{2}$, C.M.M. Campos $^{3}$, F.L. Silva ${ }^{4}$ \\ ${ }^{1}$ Engenheiro Agrícola \\ ${ }^{2}$ Universidade Federal de Minas Gerais \\ ${ }^{3}$ Universidade Federal de Lavras \\ ${ }^{4}$ Médico Veterinário
}

\section{RESUMO}

Avaliou-se o efeito de inóculos (tratamentos) na degradação dos dejetos líquidos de suínos, em diferentes tempos de detenção hidráulica $(0,30,60,90,120,150,180$ horas). Foram utilizados um inóculo comercial, na dose recomendada pelo fabricante, três inóculos alternativos à base de esterco bovino, cama de frango e esgoto doméstico, todos aplicados na dose de $5 \mathrm{ml} / 1$, e um tratamento-controle, sem inóculo. Foi utilizado o delineamento inteiramente ao acaso, em esquema de parcelas subdivididas, empregando-se três repetições. Após cada tempo de detenção foram realizadas as seguintes análises: $\mathrm{pH}$, demanda bioquímica de oxigênio (DBO), demanda química de oxigênio, sólidos totais, sólidos totais voláteis e sólidos sedimentáveis, temperaturas do ar e do líquido. Os inóculos comercial e alternativo à base de cama de frango promoveram maior redução de DBO que os demais, 68,5\% e 67,5\%, respectivamente.

Palavras-chave: suínos, digestão anaeróbia, ensaio in vitro

\section{ABSTRACT}

The effect of seeding material (treatments) upon degrading liquid waste of swine was evaluated at different hydraulic retention times (0,30,60, 90, 120, 150, 180 hours). A commercial seeding material according to the recommended manufacture dosage, three alternative seeding materials based on bovine manure, chicken manure, and domestic sewage, all of them applied at the dosage of $5 \mathrm{ml} / \mathrm{l}$, and a control treatment (without seeding material) were used. An entirely randomized design was set to study the subdivided fragments using three repetitions. After each detention time, the following analyses have been performed: $\mathrm{pH}$, biochemical oxygen demand (BOD), chemical oxygen demand, total solids, total volatile solid, settling solids, air and liquid temperatures. The commercial and alternative seeding materials based on chicken waste promoted a higher reduction of BOD than the other ones, $68.5 \%$ and $67.5 \%$, respectively.

Keywords: swine, anaerobic digestion, in vitro analysis

Recebido para publicação em 25 de abril de 2003

Recebido para publicação, após modificações, em 1 de setembro de 2004

*Endereço para correspondência:

R. Antônio Augusto Faria, 47 - Lavrinhas

37200-000 - Lavras, MG

E-mail: 1sr@ufla.br 


\section{INTRODUÇÃO}

A demanda por carne suína e seus derivados estimulou a expansão da criação de suínos, resultando na intensificação de criatórios em confinamento. Isso trouxe, como conseqüência, aumento da quantidade de dejetos produzidos, os quais inadequadamente tratados e reaproveitados passaram a causar poluição ambiental. A nova realidade do mercado consumidor, exigindo produtos de qualidade, preços competitivos e oriundos de sistemas não-poluidores do ambiente, passou a exercer crescente pressão para a reciclagem desses resíduos, dentro de padrões aceitáveis sob o ponto de vista sanitário, econômico e ambiental (Seganfredo, 2000). Por isso, o estudo de alternativas de tratamento dos efluentes provenientes da suinocultura tornou-se necessário.

A utilização de microrganismos promotores de degradação de resíduos orgânicos tem sido uma alternativa que deve ser considerada no sistema de tratamento de dejetos de suínos, pois há vários trabalhos que mostram a eficiência do processo de bioaumento no tratamento desse tipo de resíduo. Schneider (1991) relatou a utilização de bactérias na redução da amônia em criações de suínos. Nesse caso, os tanques que receberam os dejetos foram tratados diariamente com as bactérias, trazendo, como conseqüência, redução do nitrogênio amoniacal (amônia) e, com isso, redução do odor, da população de moscas e da acumulação de sólidos. Um outro estudo sobre utilização de microrganismos no tratamento de dejetos de suínos foi realizado na Inglaterra, onde se verificou que, depois de várias semanas de tratamento, o nível de amônia diminuiu em até $50 \%$. Essa redução foi constante por vários meses, com tratamento diário contínuo (Isbizuka, 1997).

Este trabalho teve o objetivo de avaliar a eficiência de diferentes inóculos na redução da carga orgânica dos efluentes de suinocultura.

\section{MATERIAL E MÉTODOS}

Os dejetos de suínos utilizados para a condução do experimento foram provenientes dos setores de recria e terminação da suinocultura da Fazenda Experimental da Escola de Veterinária da UFMG. Foram utilizados 220 litros de dejetos, colocados em recipientes de politeriftalato de etileno (PET) de cor verde e com capacidade para dois litros, onde foram realizados os ensaios de digestão anaeróbia.

Foram utilizados um inóculo comercial desodorizante recomendado para lagoas anaeróbias, contendo os componentes básicos antiespumante, propionato de cálcio, água e extrato de Yucca schidigera $(10 \%$ por $\mathrm{kg}$ de produto), denominado de inóculo $\mathrm{A}$, e três inóculos alternativos, preparados a partir de esterco fresco de bovino, de resíduos de cama de frango e de esgoto fresco proveniente de uma estação de tratamento de esgoto (ETE), denominados de inóculos $\mathrm{B}, \mathrm{C}$ e $\mathrm{D}$, respectivamente.

Para preparação dos inóculos à base de esterco bovino (B) e de cama de frango (C) foram coletados resíduos nas instalações da própria fazenda. Eles foram diluídos na proporção de 2:1 (água:esterco) para o inóculo à base de esterco bovino e 3:1 (água:cama de frango), para o inóculo à base de cama de frango, peneirados e deixados em repouso por 24 horas, para posterior inoculação, que se procedeu em temperatura ambiente, na dose de $5 \mathrm{ml} / 1$.

Para o preparo do inóculo à base esgoto doméstico (D) procedeu-se a coleta do esgoto fresco, na ETE do laboratório de instalações piloto (LIPI) do Departamento de Engenharia Sanitária e Ambiental da Escola de Engenharia da UFMG, que foi deixado em repouso por 48 horas para posterior inoculação, em temperatura ambiente na dose de $5 \mathrm{ml} / 1$.

Foi utilizado um tratamento-controle sem a inclusão de inóculos.

As características dos inóculos alternativos são apresentados na Tab. 1.

Fez-se análise de variância com o objetivo de se verificar o efeito do inóculo ou da interação entre inóculos e o tempo de detenção hidráulica (TDH). Utilizou-se o teste Tukey para comparar as médias dos inóculos dentro de cada TDH. Para comparar o efeito do TDH dentro de cada inóculo foi feita análise de regressão. 
Avaliação in vitro da eficiência de inóculos...

Tabela 1. Principais características físico-químicos dos inóculos alternativos

\begin{tabular}{lccc}
\hline Característica & Esterco bovino & Cama de frango & Esgoto doméstico \\
\hline Estado físico & Líquido & Líquido & Líquido \\
Aparência & Líquido turvo & Líquido turvo & Líquido turvo \\
Odor & Característico & Característico & Característico \\
Cor & Verde-escuro & Amarelo-palha & Cinza-escuro \\
Toxicidade & Não- avaliada & Não- avaliada & Não- avaliada \\
Demanda bioquímica de oxigênio & $4260 \mathrm{mg} / 1$ & $3505 \mathrm{mg} / 1$ & $191 \mathrm{mg} / 1$ \\
Demanda química de oxigênio & $10578 \mathrm{mg} / 1$ & $4657 \mathrm{mg} / 1$ & $349 \mathrm{mg} / 1$ \\
PH & 7,25 & 7,04 & 7,0 \\
Alcalinidade & $1864 \mathrm{mg} / 1$ & $4115 \mathrm{mg} / 1$ & $168 \mathrm{mg} / 1$ \\
Acidez & $278 \mathrm{mg} / 1$ & $616 \mathrm{mg} / 1$ & $32 \mathrm{mg} / 1$ \\
Nitrogênio amoniacal & $74,5 \mathrm{mg} / 1$ & $1021 \mathrm{mg} / 1$ & $40,32 \mathrm{mg} / 1$ \\
Sólidos Totais & $13814 \mathrm{mg} / 1$ & $5853 \mathrm{mg} / 1$ & $973 \mathrm{mg} / 1$ \\
\hline
\end{tabular}

\section{RESULTADOS E DISCUSSÃO}

As temperaturas do ar (TA), do líquido (TL) e máximas (TAmax) e mínimas (TAmin) registradas durante o experimento encontram-se na Fig. 1. A oscilação da temperatura do líquido variou de 20 a $28^{\circ} \mathrm{C}$, não afetando o crescimento das bactérias mesófilas que segundo Chernicharo (1997) é de 20 a $45^{\circ} \mathrm{C}$.

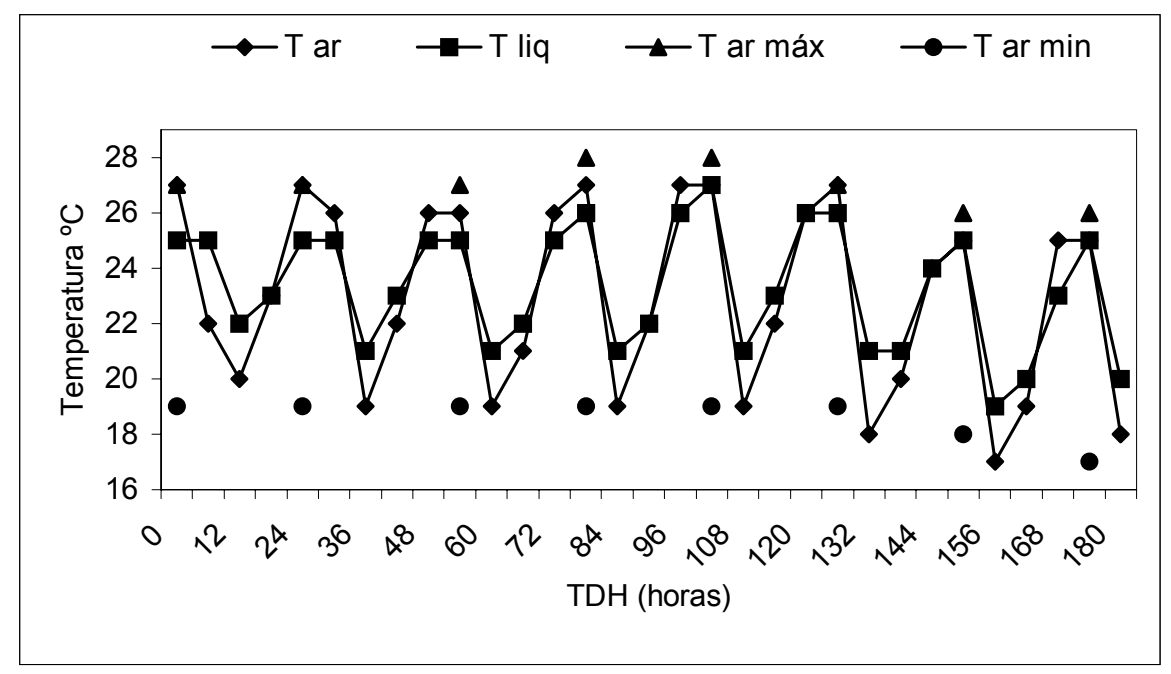

Figura 1. Temperaturas (T) do ar e do líquido segundo o tempo de detenção hidráulica (TDH).

A representação gráfica do $\mathrm{pH}$ das amostras por inóculo em função do tempo de detenção hidráulica (TDH) é apresentada na Fig. 2. O controle e os inóculos $\mathrm{A}$ e $\mathrm{B}$ proporcionaram diminuição do $\mathrm{pH}$ até o tempo 120 horas, a partir do qual houve ligeiro aumento do $\mathrm{pH}$ até o tempo 180 horas. Os inóculos C e D tiveram comportamento semelhante com diminuição do $\mathrm{pH}$ até o tempo 90 horas; a partir desse ponto, ocorreram variações não significativas no seu valor. Apenas no TDH de 120 horas houve diferença $(\mathrm{P}<0,05)$ entre os diversos tratamentos, isto é, o inóculo $\mathrm{C}$ diferiu do controle e do inóculo A. 


\section{Rodrigues et al.}

Inóculos:

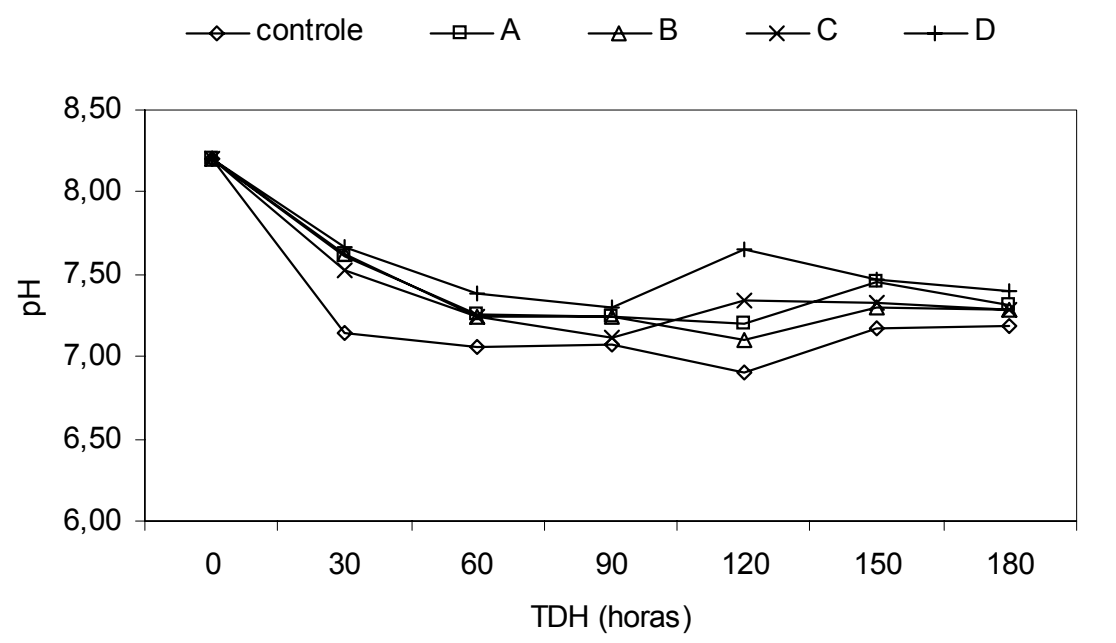

$$
\begin{array}{ll}
\mathrm{Y}_{\text {controle }}=8,145159-0,036384 \mathrm{TDH}+0,000336 * \mathrm{TDH}^{2} & \mathrm{R}^{2}=0,9261 \\
\mathrm{Y}_{\mathrm{A}}=8,224524-0,028616 \mathrm{TDH}+0,000257 * \mathrm{TDH}^{2} & \mathrm{R}^{2}=0,9728 \\
\mathrm{Y}_{\mathrm{B}}=8,213889-0,025468 \mathrm{TDH}+0,000196 * \mathrm{TDH}^{2} & \mathrm{R}^{2}=0,9773 \\
\mathrm{Y}_{\mathrm{C}}=8,215635-0,031347 \mathrm{TDH}+0,000299 * \mathrm{TDH}^{2} & \mathrm{R}^{2}=0,9870 \\
\mathrm{Y}_{\mathrm{D}}=8,227063-0,028272 \mathrm{TDH}+0,000294 * \mathrm{TDH}^{2} & \mathrm{R}^{2}=0,9300
\end{array}
$$

* Significativo a 5\% de probabilidade, pelo teste de F.

$\mathrm{Y}=$ valor estimado de $\mathrm{pH}$; TDH = tempo de detenção hidráulica

Figura 2. pH do dejeto de suínos para os diversos inóculos em relação ao tempo de detenção hidráulica (TDH).

O monitoramento do $\mathrm{pH}$ é de fundamental importância para que se consiga boa eficiência no processo anaeróbio, pois as bactérias metanogênicas são muito sensíveis às variações do $\mathrm{pH}$ (Chernicharo, 1997). De acordo com Oliveira (1993), o crescimento das bactérias metanogênicas é ótimo entre 6,8 a 7,2. Durante o experimento observou-se que o $\mathrm{pH}$ do controle e dos inóculos manteve-se na faixa ideal de crescimento dessas bactérias.

Os resultados obtidos para a demanda bioquímica de oxigênio (DBO) são apresentados na Tab. 2 e na Fig. 3. Apenas no tempo de 30 horas ocorreu diferença significativa entre $\mathrm{o}$ controle e os inóculos A e B $(\mathrm{P}<0,05)$.

Tabela 2. Valores $(*)$ da demanda bioquímica de oxigênio (DBO) em mg/l de acordo com os inóculos e os tempos de detenção hidráulica

\begin{tabular}{lccccccc}
\hline \multirow{2}{*}{ Inóculo } & \multicolumn{7}{c}{ Tempo de detenção hidráulica } \\
\cline { 2 - 8 } & 0 & 30 & 60 & 90 & 120 & 150 & 180 \\
\hline Controle & $5107 \mathrm{a}$ & $4321 \mathrm{~b}$ & $2479 \mathrm{a}$ & $2435 \mathrm{a}$ & $2117 \mathrm{a}$ & $1978 \mathrm{a}$ & $2205 \mathrm{a}$ \\
$\mathrm{A}$ & $5107 \mathrm{a}$ & $2357 \mathrm{a}$ & $2308 \mathrm{a}$ & $2082 \mathrm{a}$ & $1619 \mathrm{a}$ & $1579 \mathrm{a}$ & $1626 \mathrm{a}$ \\
$\mathrm{B}$ & $5107 \mathrm{a}$ & $2553 \mathrm{a}$ & $2553 \mathrm{a}$ & $2062 \mathrm{a}$ & $2280 \mathrm{a}$ & $1725 \mathrm{a}$ & $1934 \mathrm{a}$ \\
$\mathrm{C}$ & $5107 \mathrm{a}$ & $3732 \mathrm{ab}$ & $2529 \mathrm{a}$ & $1964 \mathrm{a}$ & $1527 \mathrm{a}$ & $2146 \mathrm{a}$ & $1663 \mathrm{a}$ \\
$\mathrm{D}$ & $5107 \mathrm{a}$ & $2946 \mathrm{ab}$ & $1841 \mathrm{a}$ & $2102 \mathrm{a}$ & $2117 \mathrm{a}$ & $2052 \mathrm{a}$ & $1885 \mathrm{a}$ \\
\hline
\end{tabular}

* média de três repetições

Médias seguidas pela mesma letra minúscula na coluna não diferem entre si pelo teste Tukey $(\mathrm{P}<0,05)$. 
Inóculos:

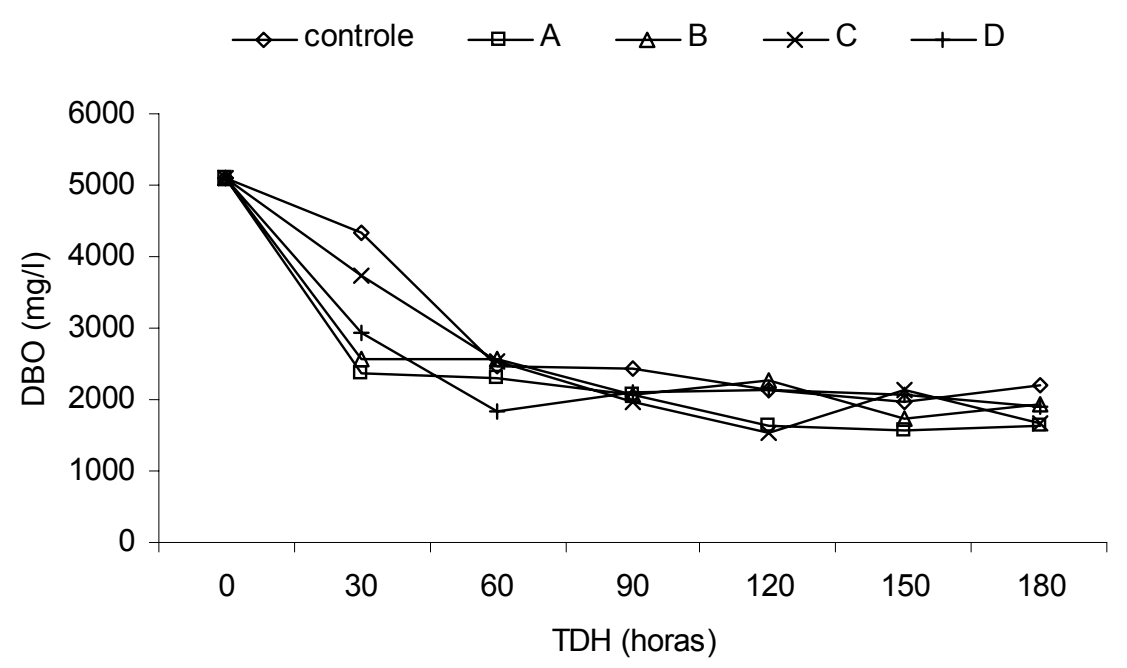

$\begin{array}{ll}\mathrm{Y}_{\text {controle }}=5230,706349-51,033245 \mathrm{TDH}+0,226958 \mathrm{TDH}^{2}-0,000202 * \mathrm{TDH}^{3} & \mathrm{R}^{2}=0,9535 \\ \mathrm{Y}_{\mathrm{A}}=4884,293651-84,688007 \mathrm{TDH}+0,738951 \mathrm{TDH}^{2}-0,002073 * \mathrm{TDH}^{3} & \mathrm{R}^{2}=0,9242 \\ \mathrm{Y}_{\mathrm{B}}=4915,047619-81,632804 \mathrm{TDH}+0,740013 \mathrm{TDH}^{2}-0,002131 * \mathrm{TDH}^{3} & \mathrm{R}^{2}=0,9180 \\ \mathrm{Y}_{\mathrm{C}}=5186,333333-66,033377 \mathrm{TDH}+0,420573 \mathrm{TDH}^{2}-0,000880 * \mathrm{TDH}^{3} & \mathrm{R}^{2}=0,9738 \\ \mathrm{Y}_{\mathrm{D}}=5083,626984-96,466049 \mathrm{TDH}+0,917377 \mathrm{TDH}^{2}-0,002679 * \mathrm{TDH}^{3} & \mathrm{R}^{2}=0,9864 \\ & \\ & \\ & \end{array}$

Figura 3. Demanda bioquímica de oxigênio do dejeto de suínos de acordo com os inóculos e os tempos de detenção hidráulica (TDH).

Para o controle e para o inóculo A a máxima redução da demanda bioquímica de oxigênio (DBO) ocorreu no tempo de 150 horas (Fig. 3), isto é, o controle apresentou eficiência máxima de $60,8 \%$ e o inóculo A de $68,5 \%$. Para os inóculos alternativos $\mathrm{B}, \mathrm{C}$ e $\mathrm{D}$, a máxima redução ocorreu no tempo de 180 horas.
Nenhum dos inóculos foi capaz de reduzir a demanda química de oxigênio (DQO) em relação ao inoculo-controle (Tab. 3).

Para todos os inóculos e para o controle a maior redução de DQO ocorreu no TDH de 60 horas, a partir do qual não houve variações (Fig. 4).

Tabela 3. Valores $\left(^{*}\right.$ ) da demanda química de oxigênio (DQO) em mg/l de acordo com os inóculos e os tempos de detenção hidráulica

\begin{tabular}{lccccccc}
\hline \multirow{2}{*}{ Inóculos } & \multicolumn{7}{c}{ Tempo de detenção hidráulica } \\
\cline { 2 - 8 } & 0 & 30 & 60 & 90 & 120 & 150 & 180 \\
\hline Controle & $17021 \mathrm{a}$ & $12273 \mathrm{a}$ & $6195 \mathrm{a}$ & $6381 \mathrm{a}$ & $8680 \mathrm{a}$ & $7654 \mathrm{a}$ & $8636 \mathrm{a}$ \\
$\mathrm{A}$ & $17021 \mathrm{a}$ & $13964 \mathrm{a}$ & $6496 \mathrm{a}$ & $5757 \mathrm{a}$ & $9750 \mathrm{a}$ & $9632 \mathrm{a}$ & $6966 \mathrm{a}$ \\
$\mathrm{B}$ & $17021 \mathrm{a}$ & $12287 \mathrm{a}$ & $8064 \mathrm{a}$ & $8097 \mathrm{a}$ & $8083 \mathrm{a}$ & $11438 \mathrm{a}$ & $12209 \mathrm{a}$ \\
$\mathrm{C}$ & $17021 \mathrm{a}$ & $14754 \mathrm{a}$ & $9184 \mathrm{a}$ & $9279 \mathrm{a}$ & $7583 \mathrm{a}$ & $3969 \mathrm{a}$ & $7654 \mathrm{a}$ \\
$\mathrm{D}$ & $17021 \mathrm{a}$ & $10096 \mathrm{a}$ & $3871 \mathrm{a}$ & $7750 \mathrm{a}$ & $7167 \mathrm{a}$ & $5588 \mathrm{a}$ & $5676 \mathrm{a}$ \\
\hline * média
\end{tabular}

Médias seguidas pela mesma letra minúscula na coluna não diferem entre si pelo teste Tukey $(\mathrm{P}<0,05)$. 
Rodrigues et al.

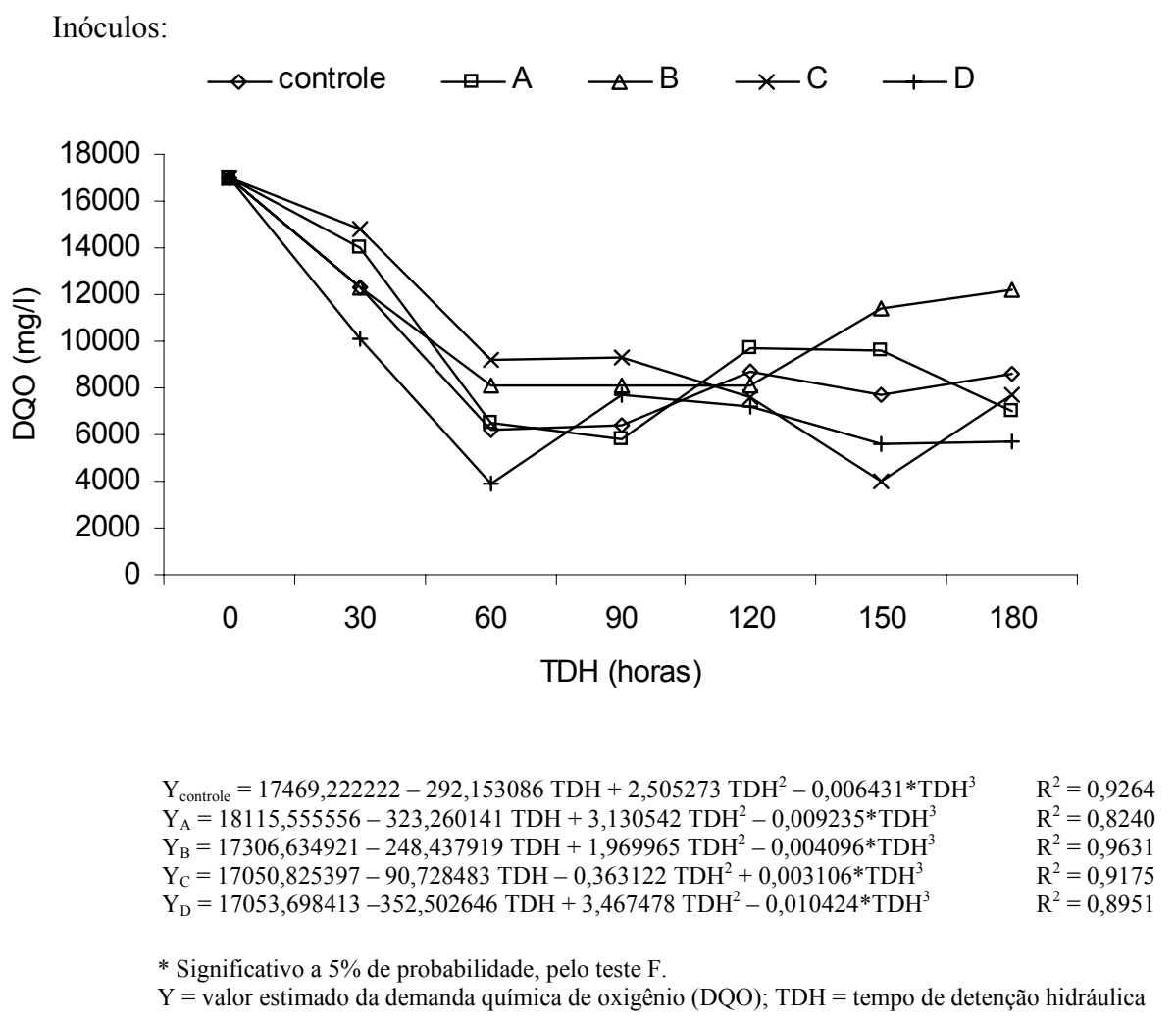

Figura 4. Demanda química de oxigênio do dejeto de suínos de acordo com os inóculos e os tempos de detenção hidráulica (TDH).

Isbizuka (1997), em uma criação de suínos no Estado de Santa Catarina, ao utilizar um produto comercial na forma de grânulos por um período de 2,5 meses, aplicado a cada 14 dias, relatou eficiência de remoção de DQO de 91,6\%. Neste trabalho, a eficiência do inóculo $\mathrm{D}$ na redução de DQO foi de 77,3\% no tempo de 60 horas, mostrando que o seu uso para remover a matéria orgânica de dejetos de suínos pode ser utilizada.

O emprego dos inóculos mostraram-se eficientes na redução tanto da DBO como DQO. Pode-se concluir que sua aplicação no sistema de tratamento de dejetos de suínos reduz sua carga orgânica.

\section{REFERÊNCIAS BIBLIOGRÁFICAS}

CHERNICHARO, C.A.L. Reatores anaeróbios. Belo Horizonte: DESA, UFMG, 1997. 247p. (Princípios do Tratamento Biológico de Águas Residuárias, v.5).

ISBIZUKA, M.M. A biotecnologia no tratamento de dejetos de suínos. Rev. Biotecnol. Ciênc. Desenv., n.3. p.16-17, 1997.

OLIVEIRA, P.A.V. Manual de manejo e utilização dos dejetos de suinos. Concórdia: EMBRAPA CNPSA. 1993. 188 p. (EMBRAPA - CNPSA, Documentos 27).

SCHNEIDER, D.R. Bioaumento: uma solução natural para problemas não naturais. Rev. Nac. Carne, n.176, p.57-59, 1991.

SEGANFREDO, M.A. Equação de dejetos. Suinoc. Industr., n.144, p.14-18, 2000. 